\title{
Striving for a more person-centered psychosis care: results of a hospital-based multi-professional educational intervention
}

Katarina Allerby ${ }^{1,2^{*}}$ (D) Anneli Goulding ${ }^{1,3}$, Lilas Ali ${ }^{4,5}$ and Margda Waern ${ }^{1,2}$

\begin{abstract}
Background: Reluctance on the part of mental health professionals constitutes an important barrier to patient participation in care. In order to stimulate person-centeredness in the inpatient care of persons with psychotic illness, we developed and tested an educational intervention for hospital staff (including psychiatrists) at all four wards at the Psychosis Clinic, Sahlgrenska University Hospital in Gothenburg, Sweden. The intervention was co-created by professionals, patients, and researchers using a participatory approach. In addition to lectures and workshops, staff created and implemented small projects to increase person-centeredness on their own wards. A primary focus was to establish a partnership between patient and staff by capturing and utilizing the patient's narrative to support active engagement in the care process. This included the development of a person-centered care plan. We hypothesized that the intervention would be associated with increased patient empowerment (primary outcome) and satisfaction with care (secondary outcome).
\end{abstract}

Methods: A before and after design was used to test group differences in patient empowerment (Empowerment Scale) and consumer satisfaction (UKU-ConSat Rating Scale). All patients receiving inpatient psychosis care during measuring periods were eligible if meeting inclusion criteria of schizophrenia spectrum disorder, age $>18$, and ability to comprehend study information. Severe cognitive deficit and inadequate Swedish language skills were exclusion criteria. Data on possible confounding variables including overall health (EQ-5D), symptom burden (PANSS), and functional ability (GAF) were collected alongside outcome measures.

Results: ANCOVAs with overall health as a confounding variable showed no group differences regarding empowerment before $(n=50)$ versus after $(n=49)$ intervention, sample mean $=2.87 / 2.99, p=.142$, eta ${ }^{2}=.02, \mathrm{Cl}=-.27-.04$. Consumer satisfaction $(n=50 / 50)$ was higher in the post-implementation group (4.46 versus 11.71, $p=.041$ eta $^{2}=.04, \mathrm{Cl}=-14.17--.31$ ).

Conclusion: The hypothesis regarding the primary outcome, empowerment, was not supported. An increase in the secondary outcome, satisfaction, was observed, although the effect size was small, and results should be interpreted with caution. Findings from this staff educational intervention can inform the development of future studies aimed at improvement of inpatient care for persons with severe mental illness.

(Continued on next page)

\footnotetext{
*Correspondence: katarina.allerby@vgregion.se

${ }^{1}$ Section of Psychiatry and Neurochemistry, Institute of Neuroscience and

Physiology, Sahlgrenska Academy, University of Gothenburg, Blå Stråket 15,

41345 Gothenburg, Sweden

${ }^{2}$ Psychosis Department, Region Västra Göraland; Sahlgrenska University

Hospital, 41345 Gothenburg, Sweden

Full list of author information is available at the end of the article
}

(C) The Author(s). 2020 Open Access This article is licensed under a Creative Commons Attribution 4.0 International License, which permits use, sharing, adaptation, distribution and reproduction in any medium or format, as long as you give appropriate credit to the original author(s) and the source, provide a link to the Creative Commons licence, and indicate if changes were made. The images or other third party material in this article are included in the article's Creative Commons. licence, unless indicated otherwise in a credit line to the material. If material is not included in the article's Creative Commons licence and your intended use is not permitted by statutory regulation or exceeds the permitted use, you will need to obtain permission directly from the copyright holder. To view a copy of this licence, visit http://creativecommons.org/licenses/by/4.0/. The Creative Commons Public Domain Dedication waiver (http://creativecommons.org/publicdomain/zero/1.0/) applies to the data made available in this article, unless otherwise stated in a credit line to the data. 
(Continued from previous page)

Trial registration: The trial was retrospectively registered at ClinicalTrials.gov June 9, 2017, identifier: NCT03182283

Keywords: Schizophrenia, Psychosis, Person-centered psychosis care, Person-centered care, Patient outcomes, Empowerment, Consumer satisfaction

\section{Background}

Persons with psychotic disorders both can and want to participate in their own care [1-3]. Their views of appropriate goals and interventions often differ from those of formal care providers [4, 5], and patients' concerns for their social needs (relationships, daily activities) are on par with those of their clinical needs [6]. However, patients experience that opportunities for involvement are lacking [7], which can contribute to dissatisfaction with care [8]. While potential advantages of the involvement of persons with complex and chronic conditions in their own care were recognized by the WHO over a decade ago [9], and emphasized more recently [10], patient participation in mental health care seems to exist primarily at a policy level [11]. According to the authors of a recent review [12], reluctance on the part of mental health professionals constitutes an important barrier to patient participation. Clinical strategies that are acceptable to both patients and staff need to be developed and implemented.

One such an approach, which brings the patient's participation to the forefront is Person-Centered Care (PCC). Although definitions of PCC vary, a common basic assumption is that health care staff must recognize the patient as a capable person, with own experiences, knowledge, and preferences. Focus is shifted from the disease to the health of the patient. The starting point is the patient's own context and priorities, which means that staff must listen to the patient's own narrative [13]. Acknowledging the patient's own capacity makes it possible for staff and patients to work as partners in the creation of a personalized plan to improve health. Principles of PCC interventions highlighted in a recent concept review included empowerment, personhood, and individualized care [12]. Concept analyses and frameworks suggest that PCC is likely to improve quality and involvement in care, increase satisfaction with care, and improve health outcomes and well-being [14-16]. In somatic care settings, PCC interventions have been associated with increased patient satisfaction and quality of care [17], as well as increased selfefficacy, shorter hospital stay, and better functional performance [18-21]. Reduced agitation and increased quality of life have been shown for persons residing in old age care settings after PCC interventions [22-25]. In psychiatric care, however, outcomes of PCC are less often reported. A recent review on PCC in inpatient settings [16] identified only 3 original research papers reporting outcomes after a PCC intervention [26-28]. Two of these were set in a psychosis care setting. One [26] was a pilot study that tested an electronic care planning system. Decreased symptoms of aggressive behavior, depression, withdrawal and psychosis were observed postintervention. The other study [27] involved an IT-based patient education service which facilitated a closer patient-nurse relationship, individualized support, and increased self-efficacy in patients. In diagnostically mixed psychiatric inpatient settings, PCC has been used as one successful feature in a complex intervention to reduce the use of restraints [28, 29]. A practice development paper described promising results after the introduction of a person-centered care plan; both staff and patients reported enhanced patient involvement in care [30].

While the above-cited studies suggest that components of PCC can seem promising for psychiatric inpatient settings, we could find no studies specifically focusing on educational interventions that target hospital staff to increase the level of person-centered care for persons with schizophrenia and similar psychoses. Therefore, we developed a hospital-based multi-professional educational intervention designed to impact on staff attitudes and routines to stimulate increased person-centeredness in the inpatient care of persons with schizophrenia and similar psychoses [31]. The purpose of the current study was to compare patientrelated outcomes before and after implementation of the educational intervention. We hypothesized that we would observe increased patient empowerment and increased patient satisfaction with care after implementation of the intervention.

\section{Methods \\ Study design}

The present study is the first of several planned studies describing outcomes from the project Person-Centered Psychosis Care (PCPC) - a staff educational intervention and implementation [31]; clinicaltrials.gov, identifier: NCT03182283. In the current study, a before and after design was used to assess patient outcomes associated with the PCPC intervention. The reporting of this study follows the CONSORT guidelines for non-pharmacologic randomized trials [32] on all points applicable to a before and after design.

\section{Study setting}

The study took place at the Psychosis Clinic, Sahlgrenska University Hospital, which provides all inpatient 
care for patients with psychotic disorders in Gothenburg, Sweden's second largest city. The inpatient services include four wards with a total of 43 beds, and all wards participated in the intervention.

\section{The PCPC intervention}

PCPC is an intervention that aims to develop a more person-centered care on inpatient wards for persons with schizophrenia spectrum disorders. We followed the framework established by Gothenburg Center for Person-Centred Care (GPCC) to operationalize the PCPC intervention. The GPCC framework focuses on capturing the patients narrative (initiating a partnership), creating care plans with the patient as an active partner (working the partnership), and documenting agreements (safeguarding the partnership) [13].

PCPC was designed with two overlapping phases. The first was an educational intervention that used a participatory design [33]. Staff members took part in lectures, workshops, and experimental learning. Lectures provided a theoretical knowledge base on person-centered care and implementation processes. Invited guests from outpatient services as well as patients with ongoing service contact participated and contributed with their knowledge and perspectives. Experimental learning involved practicing the features of the GPCC framework and creating own projects to increase person-centeredness in everyday care on the wards. The educational phase consisted of 6 days of coursework spread over a 6-month period, interspersed with practical ward-based projects testing features of PCC (see Fig. 1). The latter were supported by supervision and coaching by an outside facilitator. One third of all staff (across all professions and roles, including psychiatrists) at all four hospital wards at the Psychosis Clinic participated. In order to involve all staff in the intervention process, course participants exchanged experiences, ideas, and reflections with the rest of staff in knowledge translation activities designed to increase knowledge and awareness also in staff members who did not take part in the actual coursework. Knowledge translation activities included ward meetings for all staff, group sessions for staff supervised by PCC experts, as well as lunch dates. The latter were working lunches during which a staff member who had taken the PCC course met with two colleagues who had not, in order to facilitate knowledge exchange.

The second phase involved the implementation of staffinitiated projects and new ward routines. Examples included creating a structure to allow time and place to listen to the patient's narrative, increasing patient participation in the creation of the care plan (writing the plan together with patients or using the patient's own words), improving written information to patients, altering round routines to include patient participation, and improving cooperation with outpatient clinics to facilitate person-centered transitions from inpatient to outpatient care. As described in our study protocol [31], a steering group and an implementation group, with members from each ward, monitored the development of person-centered care activities and provided support when needed during the implementation period. Lectures and seminars were held, and a senior psychiatrist along with several of the clinic's specialists in psychiatric nursing supervised small group sessions where various aspects of person-centered care were discussed. These procedures facilitated change from within by creating an environment that encouraged continuous improvement of care without reliance on external resources.

\section{Participants}

All persons receiving inpatient care at any of the clinic's four wards during the measuring periods were potentially eligible if meeting the following criteria: age $\geq 18$
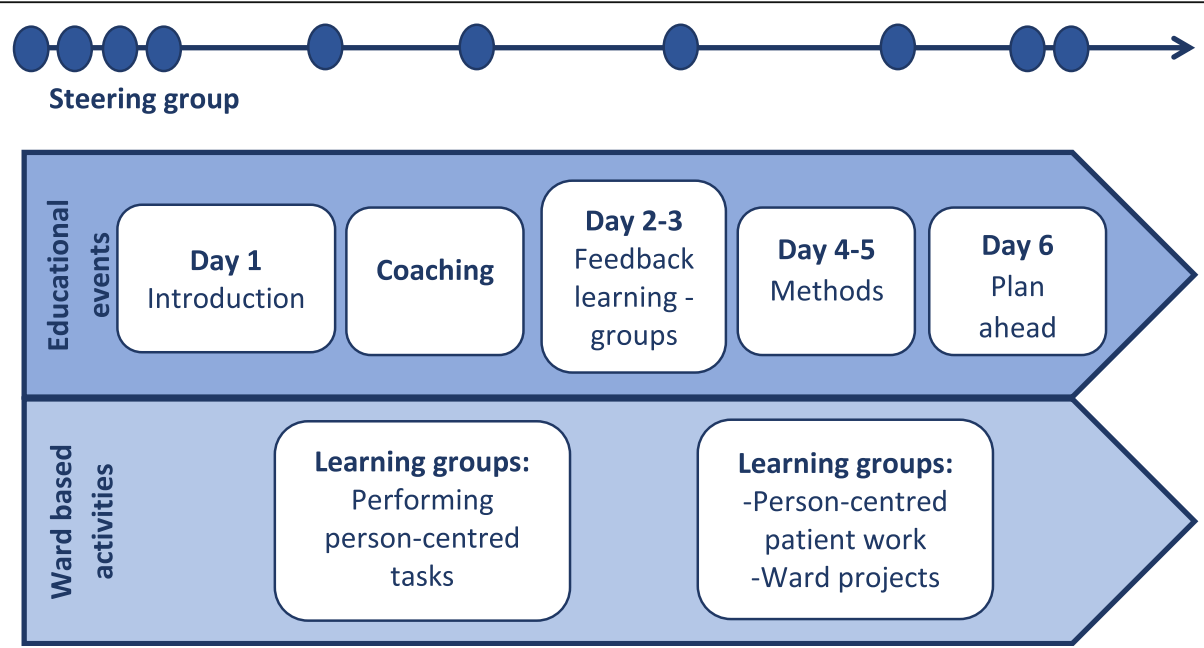

Fig. 1 The educational and experimental learning phase process. Figure 1 was originally published in our study protocol, Goulding et al. (2018), BMC Psychiatry by Springer Nature and is used here under the Creative Common License (http://creativecommons.org/licenses/by/4.0/) 
years and fulfilling criteria for a clinical diagnosis in the schizophrenia spectrum disorder (F20-F29) in accordance with ICD-10 [34]. Exclusion criteria were severe cognitive disability with inability to comprehend study goals and procedures (as determined by the patient's psychiatrist), or lack of knowledge of the Swedish language to such a degree that an interpreter was required. The aim was to include 50 patients in each group (preand post-intervention) and sampling continued until each group was filled.

\section{Measures}

The primary outcome measure was patients' self-reported empowerment, which is an important feature of personcentered care. The Empowerment Scale [35, 36] was used, which consists of 28 items with responses given on a four point Likert-type scale ranging from "totally agree" to "totally disagree". Positive and negative statements are mixed and some items are reversed when calculating the total score so that a higher score represents greater perceived empowerment. The mean item score (the total score divided by number of items) is used to illustrate the level of empowerment. Items correspond to 5 factors of empowerment (Self-esteem - self-efficacy: i.e. "I see myself as a capable person", Power - powerlessness: "You can't fight city hall", Community activism and autonomy: "People have the right to make their own decisions even if they are bad ones", Optimism and control over the future: "Very often a problem can be solved by taking action", and Righteous anger: "Making waves never gets you anywhere"). The scale has shown good internal consistency (Cronbach's alpha $=.86$ ) and the five factors explained $54 \%$ of the variance in a validity study [35]. The scale is validated for and used internationally in studies involving persons with severe mental illness [36]. Cronbach's alpha in the current sample was .75 .

The secondary outcome measure was self-reported consumer satisfaction with health care, measured with the UKU-ConSat Rating Scale [37]. The scale contains 11 items; responses are given on a seven-point scale ranging from -3 (very bad/negative/little) to +3 (very good/positive/much) reflecting levels of satisfaction with different aspects of the care provided (e.g. opportunity to get information on care decisions, participate in decision-making, medication, and psychosocial interventions). All total scores above zero are considered to reflect satisfaction and the level of satisfaction increases with the score. Correspondingly, scores below zero reflect different levels of dissatisfaction. The ConSat scale is constructed and validated for psychiatric patients, including both in- and outpatients with psychotic disorders [37, 38]. This study used the selfrating version for consumers which has good internal consistency (Cronbach's alpha $=.80$ ). Correlations with the original interview version of the scale showed Pearson $r$ ranging from .67 to .82 [39]. Cronbach's alpha in our PCPC sample was .88 .

Possible confounders including symptom burden, functional ability, and overall health were quantified for each patient at study inclusion. Symptom burden was rated with the Remission sub-scale (RSS) of the Positive and Negative Syndrome Scale, which consists of 8 items that reflect core symptoms of schizophrenia [40]. The scores $(1=$ non-existing symptom to 7 = extremely severe symptom) were based on interviews with the patient and his/ her contact person (staff). Functional ability was determined using the GAF Scale [41] which grades function on a $1-100$ scale $(100=$ fully functional in all life domains $)$. Scoring was done by the participant's contact person at the hospital ward. Overall health was self-rated with the $E Q-5 D$ Scale [42], which consists of 5 items that reflect function and discomforts and yields a total health index ranging from - 0,594 to 1 (full health). The EQ-5D scale also includes a visual analogue scale rating subjective level of overall health. The overall health scale ranges between 1 and 100 (best imaginable health).

\section{Procedure}

Patients were recruited for the pre-intervention group from May 2014 until December 2014. The educational intervention took place from December 2014 until May 2015, followed by implementation work. Post-intervention recruitment took place from May 2017 until February 2018. Patients who were soon to be discharged and met the inclusion criteria were informed about the study by one of the authors (KA, AG or LA) if available on days when the researchers were present at the clinic. All participants were given written and oral information about the study goals, procedures, and data management. They were informed that participation was voluntary and that it was possible to withdraw from participation without having to give any explanation. All signed a consent form before participating in any study-related task, and all received a copy of the signed consent and study information. The procedures conformed with the principles outlined in the Declaration of Helsinki [43] and were approved by the Regional Ethical Review Board (DNr 773-13). A researcher administered the selfrating questionnaires, assisting patients when needed. All data collection took place on the wards prior to discharge. Core symptoms were rated by the researcher with the RSS. The staff member assigned as the patient's contact person was interviewed to complete the observer section of the RSS and the GAF assessment. Information regarding age, diagnosis, form of care (voluntary/compulsory), and length of inpatient stay was collected from medical records.

\section{Statistical analyses}

The patient sample size was based on a power calculation of the primary outcome (Empowerment). The power 
calculation was based on independent samples t-test and showed that a total sample size of 84 participants (42 per group in a balanced design) yields $80 \%$ power to detect a .2 difference in mean item score between groups when preintervention and post-intervention scores are compared with a two-tailed test at a significance level of 05 .

The distributions of the continuous variables were studied to determine whether parametric or non-parametric analyses could be employed when analyzing group differences. The Chi-square test was used to analyze dichotomized data and Students t-test for continuous variables in background and possible covariate data. Two-tailed tests were used and $p$-values less than .05 were considered statistically significant.

Data distributions allowed parametric testing for both the Empowerment and UKU ConSat scales. ANCOVAs were used to analyze group differences, adjusting for covariates. Four potential outliers were identified among the pre-implementation participants regarding Empowerment. Two of these persons rated high levels of empowerment, two rated low levels. Four potential outliers were identified in the UKU ConSat data, one among the pre- and three among the post-intervention participants. These persons rated low levels of satisfaction. Analyses were carried out both with and without the outlier cases.

Ratings with single missing items were included in the analyses and handled as follows. A single missing item on the Empowerment scale was replaced by the participant's subscale mean. A single missing item on the UKU-ConSat was replaced by the middle alternative (0). In accordance with EQ-5D instructions [44], missing items were left blank when calculating the index score. One participant could not complete the empowerment scale due to fatigue; the rating was thus excluded. Two further participants were too fatigued to complete the RSS interview. GAF data were missing for one of these as well as for another participant, due to staff unavailability.

\section{Results}

Patients fulfilling inclusion criteria $(n=185)$ were approached, and 102 agreed to participate. Two of these started to fill out the questionnaires but chose not to continue after a few questions and were therefore excluded. The 83 approached patients who declined participation (labelled non-participants), did so for two main reasons; they did not want to participate (pre-implementation nonparticipants $n=43$; post-implementation non-participants $n=34$ ) or they wanted to participate but did not want to sign the consent form or wanted a monetary compensation for participating (pre-implementation non-participants $n=$ 5; post-implementation non-participants $n=1$ ).

Table 1 shows patient characteristics by participations status. Almost half of the participants were women.
Most were admitted in accordance with involuntary care legislation. Schizophrenia and Unspecified non-organic psychosis were the most common diagnoses. The mean length of stay was 50.7 days $(S D=49.1, M d=39.0)$ for the pre-implementation participants and 64.6 days $(S D=$ 55.5, $M d=49.5)$ for the post-implementation participants. There were no differences between groups regarding age, gender, diagnosis or involuntary care status.

Fisher's exact test, t-test, $\mathrm{Chi}^{2}$-test, and Mann-Whitney U-test were used to test differences between participants and non-participants. In the pre-implementation sample, the proportion of persons with a clinical diagnosis of schizophrenia was significantly greater among nonparticipants compared with participants who more often had a non-specified psychosis diagnosis (Fisher's exact test $=8.52$, two-tailed $p=.035$ ). No significant differences were detected between the two groups regarding age, gender, length of stay or proportions with involuntary care. There were no significant differences between participants and non-participants in the postimplementation sample.

Of the three variables included as possible confounders, both overall health, as measured by EQ-5D, and function, as measured by GAF, were significantly lower in the postimplementation group, see Table 2. No such difference was detected regarding the rating of core psychotic symptoms (RSS). As EQ-5D and GAF correlated significantly (Pearson $r=.31, p=.002$ ), we decided to use EQ-5D as a covariate in the ANCOVA analyses since this measure was considered more reliable and valid. A post hoc analysis of the ConSat scale item 8, which rates satisfaction with medication, was conducted to explore potential differences related to medication satisfaction. No difference was found between the pre- and post-intervention groups $(M=0.32$ vs $0.43 ; t(98)=-.292, p=.771)$.

Table 2 shows mean Empowerment and Consumer Satisfaction scores for the pre- and post-intervention groups. Empowerment item mean scores ranged from 2.29-3.89 in the pre-implementation group, and 2.21-3.57 postintervention. Corresponding figures for satisfaction total scores were -33-27 and -26-31 respectively.

The estimated marginal mean Empowerment value was numerically higher in the post-intervention group but the difference was not significant, and excluding outliers reduced the difference further (Table 3). Thus, the hypothesis regarding the primary outcome, increased empowerment, was not supported.

The estimated marginal mean for Consumer satisfaction was significantly higher in the post-intervention group compared to the pre-intervention group (Table 3). The hypothesis regarding the secondary outcome, increased satisfaction, was thus supported. The difference between the groups was more pronounced after the exclusion of outliers (Table 3 ). 
Table 1 Patient characteristics by participation status

\begin{tabular}{|c|c|c|c|c|}
\hline \multirow[t]{2}{*}{ Characteristic } & \multicolumn{2}{|l|}{ Pre-implementation } & \multicolumn{2}{|l|}{ Post-implementation } \\
\hline & Participants $(n=50)$ & Non-participants $(n=48)$ & Participants $(n=50)$ & Non-participants $(n=35)$ \\
\hline Mean age (SD) & $48.0(14.7)$ & $49.9(13.9)$ & $46.9(15.4)$ & $46.4(14.1)$ \\
\hline \multirow[t]{2}{*}{ Age range } & $20-78$ & $27-77$ & $19-84$ & $21-88$ \\
\hline & $n(\%)$ & $n(\%)$ & $n(\%)$ & $n(\%)$ \\
\hline Women & $23(46)$ & $24(50)$ & $20(40)$ & $15(43)$ \\
\hline Involuntary care & $35(70)$ & $39(81)$ & $31(62)$ & $25(71)$ \\
\hline Schizophrenia & $16(32)$ & $26(54)$ & $15(30)$ & $13(37)$ \\
\hline Schizoaffective disorder & $11(22)$ & $13(27)$ & $10(20)$ & $7(20)$ \\
\hline Delusional disorder & $6(12)$ & $2(4)$ & $10(20)$ & $3(9)$ \\
\hline Unspecified nonorganic psychosis & $17(34)$ & $7(15)$ & $15(30)$ & $12(34)$ \\
\hline
\end{tabular}

\section{Discussion}

We applied a participatory approach to the development and implementation of a multi-professional educational intervention for staff involved in inpatient care for persons with schizophrenia spectrum disorders. We did not find support for our hypothesis that empowerment would be significantly higher in the post-intervention group, but an increase in patient satisfaction with care was observed, although the effect size was small. As publications on participatory approaches to increase PCC are rare, especially in the psychiatric setting, our results can help to inform the development and testing of new approaches to inpatient care for persons with schizophrenia and similar psychoses.

There may be different explanations for the observed lack of improvement in empowerment. First, it is possible that our intervention did not actually improve the level of person-centeredness on the wards to a degree sufficient to impact on patients' feelings of empowerment. Another possibility is that the intervention did indeed improve person-centeredness, but that the latter did not affect empowerment. This is however theoretically contradictory since empowerment is tightly connected with several aspects of PCC and stressed in PCC concept analyses [12, 45]. The phenomenon of empowerment encompasses numerous elements related to the experience of being in control of determinants of quality of life, including health, relationships, work/economy, and living/home [46]. While the PCPC intervention might affect several of these aspects, it targets mainly health-related issues, and it is possible that affecting this particular aspect does not raise the overall experience of empowerment. Further, the empowerment scale employed in this study captures empowerment on an overall level. The measure was constructed on the basis of mental health service users' own perspectives of empowerment, which is in line with PCC. However, the scale addresses the whole life perspective and some items (for example "You can't fight city hall", "People are limited only by what they think possible") might lack relevance in our clinical context. It is possible that a scale focusing more specifically on empowerment in care situations would yield a different result.

Table 2 Ratings of background and outcome variables in patient participants before and after PCPC implementation

\begin{tabular}{|c|c|c|c|c|}
\hline Measure & $\begin{array}{l}\text { Pre-implementation participants }(n=50)^{\mathrm{a}} \\
M(S D)\end{array}$ & $\begin{array}{l}\text { Post-implementation participants }(n=50) \\
M(S D)\end{array}$ & $\begin{array}{l}\text { Two-tailed } \\
t(p)\end{array}$ & $\begin{array}{l}95 \% \mathrm{Cl} \text { of } \\
\text { mean } \\
\text { difference }\end{array}$ \\
\hline \multicolumn{5}{|l|}{ Background variables } \\
\hline EQ-5D Index & $.62(.38)$ & $-.05(.31)$ & $9.56(<.0005)$ & $.53-.81$ \\
\hline EQ-5D VAS & $65.99(25.04)$ & $52.76(24.47)$ & $2.67(.009)$ & $3.40-23.06$ \\
\hline GAF Function subscale & $67.06(15.12)$ & $55.22(13.60)$ & $4.08(<.0005)$ & $6.08-17.60$ \\
\hline GAF Symptom subscale & $60.24(15.78)$ & $48.86(15.13)$ & $3.67(<.0005)$ & $5.22-17.55$ \\
\hline PANSS RSS & $14.67(5.56)$ & $13.10(4.19)$ & $1.58(.117)$ & $-.40-3.53$ \\
\hline \multicolumn{5}{|l|}{ Outcome variables } \\
\hline Empowerment Scale & $2.95(.29)$ & $2.91(.29)$ & & \\
\hline UKU ConSat Scale & $7.11(12.44)$ & $9.06(13.15)$ & & \\
\hline
\end{tabular}

a Due to missing data in the pre-intervention sample, GAF Function subscale has $n=48$, GAF Symptom subscale $n=49$, PANSS RSS $n=48$ and Empowerment Scale $n=49$ 
Table 3 Estimated marginal means and group difference results regarding Empowerment and Consumer satisfaction

\begin{tabular}{|c|c|c|c|c|}
\hline Measure & $\begin{array}{l}\text { Pre-implementation participants } \\
\text { Estimated marginal mean }{ }^{\mathrm{a}}(S E)\end{array}$ & $\begin{array}{l}\text { Post-implementation participants } \\
\text { Estimated marginal mean }{ }^{\mathrm{a}}(S E)\end{array}$ & $\begin{array}{l}95 \% \mathrm{Cl} \text { of } \\
\text { mean } \\
\text { difference }\end{array}$ & $F(p)$ \\
\hline \multicolumn{5}{|l|}{ Empowerment } \\
\hline \multirow[t]{2}{*}{ With outliers } & $2.87(.048)$ & $2.99(.047)$ & $-.27-.04$ & $2.2(.142) e t a^{2}=.02$ \\
\hline & $n=49$ & $n=50$ & & \\
\hline \multirow[t]{2}{*}{ Without outliers } & $2.90(.047)$ & $2.96(.043)$ & $-.21-.09$ & $.64(.426) e t a^{2}=.007$ \\
\hline & $n=45$ & $n=50$ & & \\
\hline \multicolumn{5}{|c|}{ Consumer satisfaction } \\
\hline \multirow[t]{2}{*}{ With outliers } & $4.46(2.15)$ & $11.71(2.15)$ & $-14.17--.31$ & $4.29(.041)$ eta $^{2}=.04$ \\
\hline & $n=50$ & $n=50$ & & \\
\hline \multirow[t]{2}{*}{ Without outliers } & $5.81(1.78)$ & $13.46(1.89)$ & $-13.44--1.87$ & $6.91(.010)$ eta $^{2}=.06$ \\
\hline & $n=49$ & $n=47$ & & \\
\hline
\end{tabular}

${ }^{\mathrm{a}}$ EQ-5D index mean was used as covariate in the ANCOVA of both Empowerment and Consumer satisfaction data

We did find support for our hypothesis that the secondary outcome, patient satisfaction, would be greater in the post-intervention group. However, this result should be interpreted with caution as patient satisfaction was our secondary outcome and the effect size was small. The finding expands on previous results from person-centered interventions in other settings including outpatient services for persons with psychotic illness [47] and inpatient somatic care [17]. The PCPC intervention focused highly on staff-patient relations, and good relations with staff have been linked to patient satisfaction in inpatient psychiatric care in a recent review [48]. It is possible that the intervention contributed to an improvement in overall ward atmosphere, which has also been shown to contribute to inpatient satisfaction [49]. Interventions designed to improve patients' own experiences of care may have implications for prognosis, as patient satisfaction has been linked to future treatment outcomes [50].

The pre-intervention patient satisfaction score was almost identical to that reported from a recent Danish inpatient study investigating satisfaction with care using the same instrument [51], and indicates that patients in both studies were somewhat satisfied in view of the interpretation that all scores above 0 denote satisfaction. Improvement in patient satisfaction in the postintervention group was observed despite the large proportion of patients with involuntary admission. Involuntary treatment has been shown to have a negative impact on satisfaction $[48,52]$ although it has been argued that person-centered care can co-exist with involuntary treatment [53]. In a qualitative study of service users' experiences during involuntary care, positive and empowering experiences were described in the narratives [54]. The authors of the latter study concluded that informative and collaborative approaches to care may reduce the traumatic impact of involuntary admissions.
When planning this study, we were aware of possible confounding variables that might affect the results [31]. Therefore, we planned to conduct ANCOVA:s if data permitted parametric analyses. Overall health turned out to be a confounder and was therefore included as a covariate in the analyses of the outcome variables. Other possible confounding variables are age, legal status (voluntary vs involuntary care), and severity of symptoms, all of which have been linked to satisfaction in previous research [55]. This study did not find any differences regarding age, legal status or symptom severity between the pre- and postintervention groups, therefore these variables were not suspected to be confounders here. Another possible confounding factor when studying patient satisfaction is pharmacological treatment. If participants experience negative side effects or limited medication effects, this might decrease their satisfaction with care $[8,56]$. As satisfaction with medication is one of the items rated in the UKU ConSat Scale, we carried out an explorative analysis of this single item. Similar ratings were observed in the pre- and post-intervention groups, suggesting that satisfaction with pharmacological treatment was not a confounder here. However, it must be stressed that a scale designed specifically for the rating of medication side effects and efficacy might have identified confounding factors that we were unable to address in the current study.

The intervention was carried out in a real-world context, and used a participatory approach to ensure that it was fitted to the everyday clinical context. The participatory approach is anticipated to facilitate sustainable change since it builds on involvement of staff throughout the development and implementation process [57]. Initially, we considered a manualized intervention involving a monitoring research nurse. However, after discussions with an expert on the design of interventions to promote change in complex organizations, we opted for the participatory approach to boost both sustainability 
and ecological validity. Such an approach has successfully been used to implement PCC in other Swedish settings [58]. A major limitation of this approach is reduced reproducibility as the intervention is tailored for specific contexts. However, the intervention does come with a degree of standardization since it is based on core features as described in the Gothenburg framework for Person-Centered Care [13]. Adopting a participatory approach means that staff members are involved in how these core features should be implemented in their specific care context.

This study evaluates a complex intervention, which entails difficulties. It is not easy to determine the level of implementation, or "dose" of the intervention, as PCC is not a method for care provision, but rather an approach to care. The intervention was meant to shape staff attitudes and routines. While there are now several tools measuring aspects or proxies of PCC in different contexts [59, 60], none had been applied and validated in the context of care for persons with psychotic illness when we designed the current study. Reports provided by staff representatives at steering group meetings and audits of person-centered care plans were used to determine whether PCPC activities had been absorbed into everyday ward practice before conducting the post-intervention data collection. Although these reports and observations suggested an uptake of PCC, we still do not know the extent to which everyday care situations were actually person-centered. Previous studies show that the degree of engagement and interest in PCC implementation varies among staff [61], as do their perceptions of what actually constitutes PCC [62]. This might contribute to a high level of heterogeneity in the care delivered. It has also been shown that even among staff who perceive their care to be person-centered, many care situations remain "traditional" i.e. more paternalistic [63]. As health professionals may overestimate their own personcenteredness [63, 64], the addition of an objective measure of person-centeredness would constitute an important addition in future studies to determine actual implementation of person-centered practices, along with a process analysis to increase the understanding of results [65].

Another factor, related to the real world context, is staff turnover which has previously been found to negatively impact the engagement in PCC implementation [62]. During the PCPC implementation there was considerable turnover of both front-line staff and management. This meant that the time between the educational intervention and follow-up had to be prolonged in order to allow more time for implementation of staff PCPC projects into everyday ward routines.

There are other limitations that need to be discussed. The relatively small number of participants in our study made it necessary to limit the number of outcome variables. Our study lacked a recovery outcome, which is stressed by people using mental health services and researchers alike [66, 67]. One reason for not including such an outcome was the relatively short time period for inpatient care. The recovery process is expected to continue long after discharge, and thus be influenced by attitudes and routines in outpatient services. While all outpatient care providers in the catchment area utilize the Resource group - Assertive Community Treatment (R-ACT) approach [47], the degree to which this is applied varies across services.

The before and after design is a major limitation since it prevents us from drawing conclusions regarding which factors might have contributed to the observed change in consumer satisfaction. Even though randomized controlled trial protocols (RCT) have been "translated" to suit complex health care interventions [68], it is not always possible or even optimal to use an RCT design when assessing interventions in such a context [69]. Randomizing individual patients in this study would risk contamination since the intervention introduces a new way of thinking. Staff cannot be expected to "turn off" the PCPC care approach for control group patients. Randomizing two of the four wards to the PCPC intervention and two to treatment as usual was not an option since hospital logistics sometimes require that staff and patients be moved between wards. For the same reason a cross-over design was not possible. A larger RCT design with randomization at group level (service providers randomized) would be more optimal but that would be an expensive endeavor, taking the project to a regional or national level.

A randomization sampling procedure was not possible in this study. Sampling bias was decreased by approaching all eligible patients who were available on data collection days. The enrollment rate must be considered a limitation as almost half of those asked to participate declined. However, the patient characteristic data presented in Table 1 shows that participants and non-participants were similar regarding almost all measured variables, indicating that our participants can be considered representative for this psychosis care setting. We cannot generalize our findings to patients with severe cognitive impairment, severe psychotic symptoms or those who lack Swedish language competence, as these were not able to participate in the study. Another type of study design would be needed to capture these patient groups. An observational study could be an alternative for those with severe impairment. Translator services would facilitate participation of those who do not speak Swedish.

\section{Conclusions}

The current study did not find the hypothesized increase of patient empowerment following a participatory staff intervention aiming to increase PCC in inpatient psychosis units. The results indicate that patient care satisfaction 
increased. This is however a secondary outcome with low effect size and is to be interpreted with caution. This paper can help to inform the future development of hospital-based PCC for persons with schizophrenia and similar psychoses. Coming papers from this project will report outcomes on ward level data as well as staff, patient and next-of-kin experiences, which will contribute to the overall understanding of PCC in a psychiatric setting.

\begin{abstract}
Abbreviations
ANCOVA: Analysis of Covariance; Cl: Confidence Interval; GAF: Global Assessment of Functioning; GPCC: Gothenburg Center for Person-Centred Care; ICD-10: International Statistical Classification of Diseases and Related Health Problems - Tenth Revision; PANSS: Positive and Negative Syndrome Scale; PCC: Person-Centered Care; PCPC: Person-Centered Psychosis Care; RCT: Randomized Controlled Trial; SD: Standard Deviation; UKU-ConSat : UKU-Consumer Satisfaction Scale; WHO: World Health Organization
\end{abstract}

\section{Acknowledgements}

We would like to thank all patients for participating in the study. We would also like to thank all inpatient staff at the Psychosis Department and members of the PCPC steering group. Special thanks to Pia Rydell, Head of the Psychosis Clinic, Sahlgrenska University Hospital, who made the project possible.

\section{Authors' contributions}

MW initiated the study; she is the project leader and grant holder. AG and LA were involved in the conception of the study. AG, LA and KA made substantial contributions to the study design. KA drafted the initial version of the manuscript and all authors took part in critical revision. All authors approved the final draft.

\section{Funding}

The study is funded by grants from FORTE (the Swedish Research Council for Health, Working Life and Welfare), grant number 2014-4510, the Gothenburg Centre for Person-Centred Care, Dahren's fund, the Psychosis Clinic at Sahlgrenska University Hospital, Gothenburg, and the Swedish state under an agreement between the Swedish government and the county councils concerning economic support of research (ALF). The funding bodies were not involved in the study design, in the collection, analysis, and interpretation of data, or in writing the manuscript. Open Access funding provided by Gothenburg University Library.

\section{Availability of data and materials}

In accordance with our ethics review board, the datasets generated and analyzed during the current study are not publicly available for ethical reasons, but are available from the corresponding author on reasonable request.

\section{Ethics approval and consent to participate}

The study was approved by the Regional Ethics Board in Gothenburg, registration number 773-13, and adheres to the Helsinki declaration [44]. All participants received study information, including statements on voluntary participation, and signed a consent form. All patients were adults and all were assessed, by their psychiatrist, to have the level of cognitive ability required to make an informed decision about study participation. Thus, consent from the parent or legal guardian was not collected.

\section{Consent for publication}

\section{Not applicable.}

\section{Competing interests}

The authors declare that they have no competing interests.

\section{Author details}

'Section of Psychiatry and Neurochemistry, Institute of Neuroscience and Physiology, Sahlgrenska Academy, University of Gothenburg, Blå Stråket 15, 41345 Gothenburg, Sweden. ${ }^{2}$ Psychosis Department, Region Västra Göraland: Sahlgrenska University Hospital, 41345 Gothenburg, Sweden. ${ }^{3}$ Department of
Psychology, University of Gothenburg, Haraldsgatan 1, 41314 Gothenburg, Sweden. ${ }^{4}$ Institute of Health Care Sciences, Centre for Person-Centred Care, Sahlgrenska Academy, University of Gothenburg, Box 100, 40530 Gothenburg, Sweden. ${ }^{5}$ Psychiatry Department, Region Västra Götaland, Sahlgrenska University Hospital, 41345 Gothenburg, Sweden.

Received: 12 August 2020 Accepted: 15 September 2020

Published online: 04 November 2020

\section{References}

1. Hamann J, Langer B, Winkler V, Busch R, Cohen R, Leucht S, et al. Shared decision making for in-patients with schizophrenia. Acta Psychiatr Scand. 2006;114(4):265-73.

2. Hamann J, Cohen R, Leucht S, Busch R, Kissling W. Do patients with schizophrenia wish to be involved in decisions about their medical treatment? Am J Psychiatry. 2005;162(12):2382-4.

3. Kinter E, Schmeding A, Rudolph I, dos Reis S, Bridges J. Identifying patientrelevant endpoints among individuals with schizophrenia: an application of patient-centered health technology assessment. Int J Technol Assess Health Care. 2009;25(1):35-41.

4. Lasalvia A, Boggian I, Bonetto C, Saggioro V, Piccione G, Zanoni C, et al. Multiple perspectives on mental health outcome: needs for care and service satisfaction assessed by staff, patients and family members. Soc Psychiatry Psychiatr Epidemiol. 2012:47(7):1035-45.

5. Fischer E, Shumway M, Owen R. Priorities of consumers, providers, and family members in the treatment of schizophrenia. Psychiatr Serv. 2002; 53(6):724-9.

6. Klein E, Rosenberg J, Rosenberg S. Whose treatment is it anyway? The role of consumer preferences in mental health care. Am J Psychiatr Rehabili. 2007;10(1):65-80.

7. Storm M, Davidson L. Inpatients' and providers' experiences with user involvement in inpatient care. Psychiatry Q. 2010;81(2):111-25.

8. Chue P. The relationship between patient satisfaction and treatment outcomes in schizophrenia. J Psychopharmacol. 2006;20(6 Suppl):38-56

9. Nolte E, McKee M. Caring for people with chronic conditions: a health system perspective. Maidenhead: McGraw-Hill Education (UK); 2008.

10. WHO. WHO global strategy on people-centred and integrated health services: interim report. Geneva: World Health Organization; 2015.

11. Stomski N, Morrison P. Participation in mental healthcare: a qualitative meta-synthesis. Int J Ment Health Syst. 2017;11(1):67.

12. Smith $G$, Williams $T$. From providing a service to being of service: advances in person-centred care in mental health. Curr Opin Psychiatry. 2016;29(5):292-7.

13. Ekman I, Swedberg K, Taft C, Lindseth A, Norberg A, Brink E, et al. Personcentered care-ready for prime time. Eur J Cardiovasc Nurs. 2011;10(4):248-51.

14. Morgan S, Yoder L. A concept analysis of person-centered care. J Holist Nurs. 2012;30(1):6-15.

15. McCormack B, McCance T. Development of a framework for person-centred nursing. J Adv Nurs. 2006;56(5):472-9.

16. Gabrielsson S, Sävenstedt S, Zingmark K. Person-centred care: clarifying the concept in the context of inpatient psychiatry. Scand J Caring Sci. 2015; 29(3):555-62.

17. Wolf $D$, Lehman $L$, Quinlin R, Zullo T, Hoffman L. Effect of patient-centered care on patient satisfaction and quality of care. J Nurs Care Qual. 2008;23(4): $316-21$

18. Ekman I, Wolf A, Olsson L-E, Taft C, Dudas K, Schaufelberger M, et al. Effects of person-centred care in patients with chronic heart failure: the PCC-HF study. Eur Heart J. 2012;33(9):1112-9.

19. Olsson L-E, Karlsson J, Ekman I. Effects of nursing interventions within an integrated care pathway for patients with hip fracture. J Adv Nurs. 2007; 58(2):116-25.

20. Olsson L-E, Karlsson J, Berg U, Kärrholm J, Hansson E. Person-centred care compared with standardized care for patients undergoing total hip arthroplasty—a quasi-experimental study. J Orthop Surg Res. 2014;9(1):95.

21. Fors A, Ekman I, Taft C, Bjorkelund C, Frid K, Larsson M, et al. Person-centred care after acute coronary syndrome, from hospital to primary care - a randomised controlled trial. Int J Cardiol. 2015;187:693-9.

22. Chenoweth L, Forbes I, Fleming R, King M, Stein-Parbury J, Luscombe G, et al. PerCEN: a cluster randomized controlled trial of person-centered residential care and environment for people with dementia. Int Psychogeriatr. 2014;26(7):1147-60. 
23. Livingston G, Kelly L, Lewis-Holmes E, Baio G, Morris S, Patel N, et al. Nonpharmacological interventions for agitation in dementia: systematic review of randomised controlled trials. Br J Psychiatry. 2014;205(6):436-42.

24. Yasuda M, Sakakibara $H$. Care staff training based on person-centered care and dementia care mapping, and its effects on the quality of life of nursing home residents with dementia. Aging Ment Health. 2017;21(9):991-6.

25. Ballard C, Corbett A, Orrell M, Williams G, Moniz-Cook E, Romeo R, et al. Impact of person-centred care training and person-centred activities on quality of life, agitation, and antipsychotic use in people with dementia living in nursing homes: a cluster-randomised controlled trial. PLoS Med. 2018;15(2):e1002500.

26. Doran D, Paterson J, Clark C, Srivastava R, Goering P, Kushniruk A, et al. A pilot study of an electronic interprofessional evidence-based care planning tool for clients with mental health problems and addictions. Worldviews Evid Based Nurs. 2010;7(3):174-84

27. Anttila M, Koivunen M, Välimäki M. Information technology-based standardized patient education in psychiatric inpatient care. J Adv Nurs. 2008;64(2):147-56.

28. Wale J, Belkin G, Moon R. Reducing the use of seclusion and restraint in psychiatric emergency and adult inpatient services_-improving patientcentered care. Perm J. 2011;15(2):57

29. Barton S, Johnson R, Price L. Achieving restraint-free on an inpatient behavioral health unit. J Psychosoc Nurs Ment Health Serv. 2009:47(1):34-40.

30. Berger J. Incorporation of the tidal model into the interdisciplinary plan of care-a program quality improvement project. J Psychiatr Ment Health Nurs. 2006;13(4):464-7.

31. Goulding A, Allerby K, Ali L, Gremyr A, Waern M. Study protocol design and evaluation of a hospital-based multi-professional educational intervention: person-Centred psychosis care (PCPC). BMC Psychiatry. 2018;18(1):269.

32. Boutron I, Altman DG, Moher D, Schulz KF, Ravaud P. CONSORT statement for randomized trials of nonpharmacologic treatments: a 2017 update and a CONSORT extension for nonpharmacologic trial abstracts. Ann Intern Med. 2017;167(1):40-7.

33. Spinuzzi C. The methodology of participatory design. Tech Commun. 2005; 52(2):163.

34. WHO. The ICD-10 classification of mental and behavioural disorders: clinical descriptions and diagnostic guidelines. Geneva: World Health Organization; 1992.

35. Rogers S, Chamberlin J, Ellison M, Crean T. A consumer-constructed scale to measure empowerment among users of mental health services. Psychiatr Serv. 1997;48(8):1042-7.

36. Rogers S, Ralph R, Salzer M. Validating the empowerment scale with a multisite sample of consumers of mental health services. Psychiatr Serv. 2010;61(9):933-6.

37. Ahlfors U, Lewander T, Lindström E, Malt UF, Lublin H, Malm U. Assessment of patient satisfaction with psychiatric care. Development and clinical evaluation of a brief consumer satisfaction rating scale (UKU-ConSat). Nord J Psychiatry. 2000;55:71-90.

38. Malm U, Lewander T. Consumer satisfaction in schizophrenia. A 2-year randomized controlled study of two community-based treatment programs. Nord J Psychiatry. 2001;55:91-6.

39. Ivarsson B, Malm U. Self-reported consumer satisfaction in mental health services: validation of a self-rating version of the UKU-consumer satisfaction rating scale. Nord J Psychiatry. 2007:61(3):194-200.

40. Opler M, Yang L, Caleo S, Alberti P. Statistical validation of the criteria for symptom remission in schizophrenia: preliminary findings. BMC Psychiatry. 2007;7:35

41. Endicott J, Spitzer R, Fleiss J, Cohen J. The global assessment scale. A procedure for measuring overall severity of psychiatric disturbance. Arch Gen Psychiatry. 1976;33(6):766-71.

42. EuroQol Group. A new facility for the measurement of health-related quality of life. Health Policy. 1990;16(3):199-208.

43. World Medical Association. World medical association declaration of Helsinki. Ethical principles for medical research involving human subjects. Bull World Health Organ. 2001;79(4):373.

44. EuroQol Foundation. EQ-5D-3L User Guide: EuroQol Research Foundation; 2018 https://euroqol.org. [Available from: https://euroqol.org/publications/ user-guides

45. Sharma T, Bamford M, Dodman D. Person-centred care: an overview of reviews. Contemp Nurse. 2015;51(2-3):107-20.

46. Tengland P-A. Empowerment: A Conceptual Discussion. Health Care Anal. 2008;16(2):77-96.
47. Malm U, Ivarsson B, Allebeck P, Falloon I. Integrated care in schizophrenia: a 2-year randomized controlled study of two community-based treatment programs. Acta Psychiatr Scand. 2003;107(6):415-23.

48. Woodward S, Berry K, Bucci S. A systematic review of factors associated with service user satisfaction with psychiatric inpatient services. J Psychiatr Res. 2017;92:81-93.

49. Middelboe T, Schjodt T, Byrsting K, Gjerris A. Ward atmosphere in acute psychiatric in-patient care: Patients' perceptions, ideals and satisfaction. Acta Psychiatr Scand. 2001;103(3):212-9.

50. Vermeulen J, Schirmbeck N, van Tricht M, de Haan L. Investigators OoP. Satisfaction of psychotic patients with care and its value to predict outcomes. Eur Psychiatry. 2018;47:60-6.

51. Bø B, Ottesen $\varnothing$, Gjestad $R$, Jørgensen $H$, Kroken $R$, Løberg E-M, et al. Patient satisfaction after acute admission for psychosis. Nord J Psychiatry. 2016;70(5):321-8.

52. Strauss J, Zervakis J, Stechuchak K, Olsen M, Swanson J, Swartz M, et al. Adverse impact of coercive treatments on psychiatric inpatients' satisfaction with care. Community Ment Health J. 2013;49(4):457-65.

53. Geller J. Patient-centered, recovery-oriented psychiatric care and treatment are not always voluntary. Psychiatr Serv. 2012;63(5):493-5.

54. Murphy R, McGuinness D, Bainbridge E, Brosnan L, Felzmann H, Keys M, et al. Service users' experiences of involuntary hospital admission under the mental health act 2001 in the Republic of Ireland. Psychiatr Serv. 2017:68(11):1127-35.

55. Priebe $\mathrm{S}$, Miglietta E. Assessment and determinants of patient satisfaction with mental health care. World Psychiatry. 2019;18(1):30.

56. Gebhardt S, Wolak A, Huber M. Patient satisfaction and clinical parameters in psychiatric inpatients - the prevailing role of symptom severity and pharmacologic disturbances. Compr Psychiatry. 2013;54(1):53-60.

57. Bradbury H, Lifvergren S. Action research healthcare: focus on patients, improve quality, drive down costs. Healthc Manage Forum. 2016;29(6):269.

58. Edvardsson D, Sandman P, Borell L. Implementing national guidelines for person-centered care of people with dementia in residential aged care: effects on perceived person-centeredness, staff strain, and stress of conscience. Int Psychogeriatr. 2014:26(7):1171-9.

59. Edvardsson D, Innes A. Measuring person-centered care: a critical comparative review of published tools. Gerontologist. 2010;50(6):834-46.

60. Ekman N, Taft C, Moons P, Mäkitalo Å, Boström E, Fors A. A state-of-the-art review of direct observation tools for assessing competency in personcentred care. Int J Nurs Stud. 2020;103634

61. Moore L, Britten N, Lydahl D, Naldemirci Ö, Elam M, Wolf A. Barriers and facilitators to the implementation of person-centred care in different healthcare contexts. Scand J Caring Sci. 2017;31(4):662-73.

62. Friberg F, Wallengren C, Håkanson C, Carlsson E, Smith F, Pettersson M, et al. Exploration of dynamics in a complex person-centred intervention process based on health professionals' perspectives. BMC Health Serv Res. 2018;18(1):441.

63. Bolster D, Manias E. Person-centred interactions between nurses and patients during medication activities in an acute hospital setting: qualitative observation and interview study. Int J Nurs Stud. 2010;47(2):154-65.

64. Dave S, Boardman J. Person-centered care in psychiatric practice. Indian J Soc Psychiatry. 2018;34(4):333.

65. Moore G, Audrey S, Barker M, Bond L, Bonell C, Cooper C, et al. Process evaluation in complex public health intervention studies: the need for guidance. J Epidemiol Community Health. 2014;68(2):101-2.

66. Law H, Morrison A, Byrne R, Hodson E. Recovery from psychosis: a user informed review of self-report instruments for measuring recovery. J Ment Health. 2012:21(2):192-207.

67. Thornicroft G, Slade M. New trends in assessing the outcomes of mental health interventions. World Psychiatry. 2014;13(2):118-24.

68. Campbell M, Fitzpatrick R, Haines A, Kinmonth AL, Sandercock P, Spiegelhalter $D$, et al. Framework for design and evaluation of complex interventions to improve health. BMJ. 2000;321(7262):694-6.

69. Craig P, Dieppe P, Macintyre S, Michie S, Nazareth I, Petticrew M. Developing and evaluating complex interventions: the new Medical Research Council guidance. BMJ. 2008;337:a1655.

\section{Publisher's Note}

Springer Nature remains neutral with regard to jurisdictional claims in published maps and institutional affiliations. 